\title{
Testing of brick clay modifications as a raw material for building ceramic products
}

\author{
Jiři Šál ${ }^{1, *}$ \\ ${ }^{1}$ The Institute of Technology and Businesses in Ceske Budejovice, Czech Republic
}

\begin{abstract}
Brick clay is nowadays modified by various procedures to achieve the best properties when used for building ceramic products. In the treatment of these clays, the properties are regulated by changing the quantity of water, sharpening, lightening, venting, settling, using additives, but also by consistent homogenization, crushing, grinding and mixing. This article compares several clay bricks before and after treatment and also compares them with ceramic clay. Comparative parameters are bulk density, porosity, water absorption, compressive strength and flexural strength, long-term changes in burning and weight loss by burning.
\end{abstract}

\section{Introduction}

The influence of the final shape of the brick body has in particular the composition of the mixture and the production of the brick body.

The original raw material for ceramic products in ancient times was clay soil. Today we would not have enough of this raw material alone. The progressive development of building ceramics has reached today's mixes, the composition of which each brick is carefully guarded. The division of raw materials into building ceramics is a whole range, can be divided by origin, function in a ceramic body, plasticity, fractions, and the like.

Production of building ceramics consists of many procedures, such as the extraction of ceramic raw materials, storage and primary treatment of raw materials, processing of raw materials and mixing, production, drying and burning. Here too, the basic procedure is known to all manufacturers of building ceramics, but the specific procedure, dosing and, for example, the firing temperature is a trade secret. Last but not least, it affects the final product as well as expedition and storage.

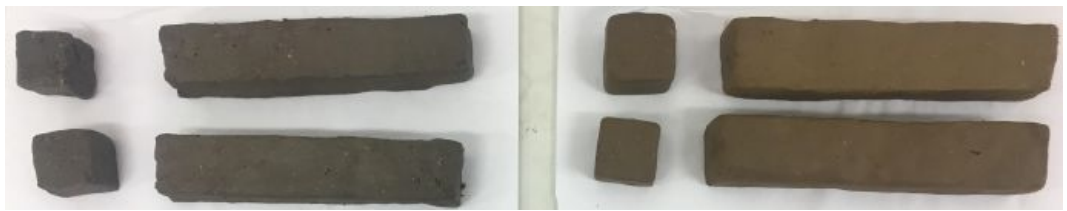

Fig. 1. Examples of brick clay samples during molding

* Corresponding author: $\underline{\text { sal@mail.vstecb.cz }}$ 
Nowadays, the properties of the brick blocks are modified or the production mixtures are modified, especially due to better thermal insulation properties. It is also a trend to use waste materials for these purposes. [1]

This article compares the production mixes with their basic raw materials, ie brick clay without any modifications and admixtures.

\section{Formation sample}

For this research, two production mixtures were selected, each from a different brick block manufactures. Both of these mixtures are prepared using all the procedures directly for pressing brick blocks. For this article, they are referred to as production mixture A and production mixture B. In addition to these mixtures, clay was rolled out without further processing. These clays serve as a basis for production mixtures. These are loess, gray clay and brick clay. The last type of soil to be considered in this article is ceramic clay, a mixture designed for the production of ceramic vases and other ornamental products. A sample example can be seen in Figure 1.

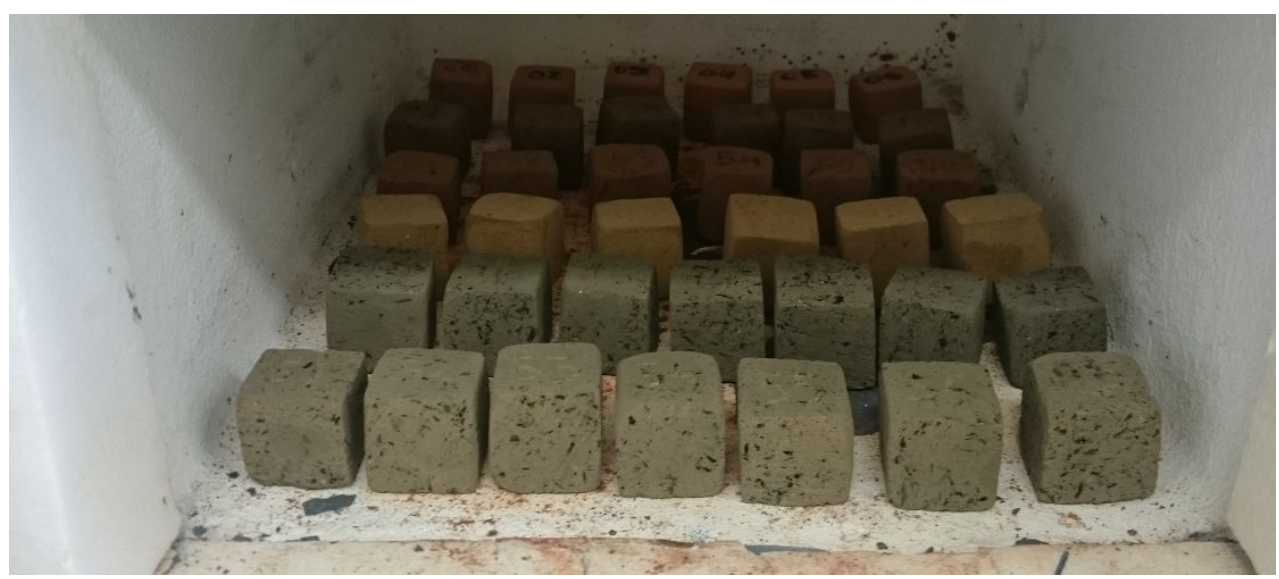

Fig. 2. Samples in a Ceramic Furnace

From each soil, 6 cubes $(20 \times 20 \times 20 \mathrm{~mm})$ and 6 frames $(20 \times 20 \times 120 \mathrm{~mm})$ were created (Fig. 2.), crush strength tests, and tensile bends for tensile strength tests. The other measured properties were tested on all of these bodies. In addition to the above-mentioned tests, weighing was also measured by burning, water absorption, apparent porosity and bulk density.

Drying was carried out in three phases, the first 24 hours covered, the other 24 exposed in air, and the third phase in an oven at $110^{\circ} \mathrm{C}$ until a constant weight. Drying was carried out according to $\breve{C S N}$. The firing was carried out according to the firing curve shown in Figure 3.

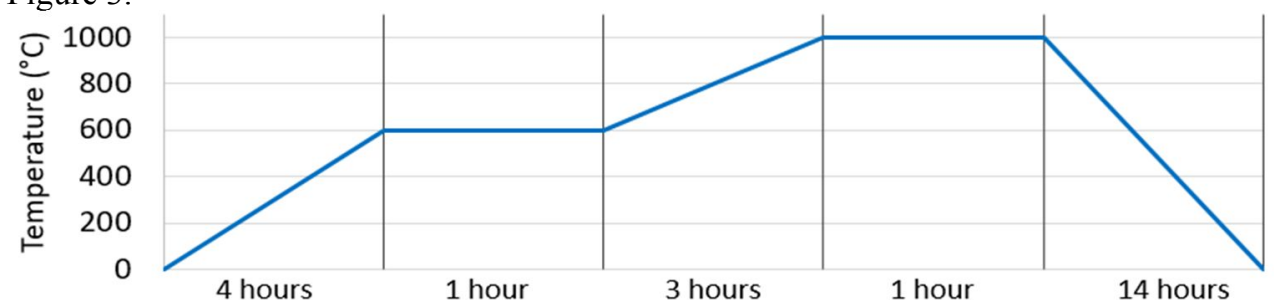

Fig. 3. Firing curve 


\section{Subject \& method of research}

The main research question of work is to monitor the differences in brick mixes versus mined raw materials. To answer these questions, sample sets were made, see the previous chapter. The following tests were subsequently performed on these samples: Long tan changes, Determination of weight loss by burning, Water absorption, Apparent porosity, Bulk density and Determination of compressive strength as well as flexural tension.

\section{Results}

The first of the observed properties was Loss of Burning Mass and Long Burning Change. Both variables are tracked due to changes in firing. The longer the length changes, the inaccuracy of the final product occurs. This may affect, for example, the accuracy of brick blocks and their subsequent grinding is needed. The lowest values were expected for the production mixtures, yet one of the production mixtures has the largest length change and $3.1 \%$, as shown in Figure 4. The length values are averaged and expressed as a percentage change from the original dimensions.

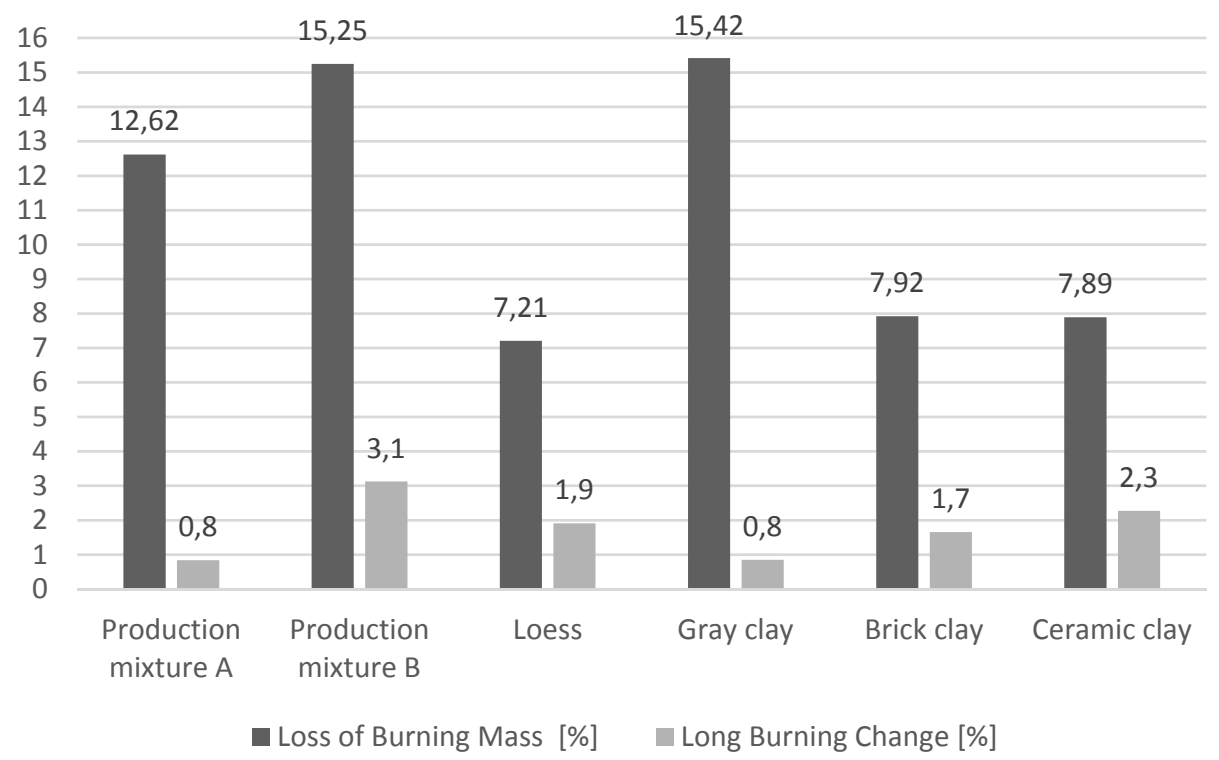

Fig. 4. Graph of Loss of Burning Mass, Long Burning Change

Loss of Burning Mass is a loss of part of the mixture that is burned when the brick is burned. Since the samples are weighed after drying, before the firing itself, the weight of the water is minimal for this assessment negligible, so the weight the sample loses is equal to the directly burnt component of the mixture. In the case of production mixtures, the burned component is lightly added deliberately and lightly already present in the clay. For extracted raw materials, they are natural light and unwanted substances. By lightening the final product by means of lighter burning, ultimately, the thermal resistance is improved. The results of this assay are also shown in Figure 3, where it is apparent that both production mixtures have a large amount of lightens. The highest value, however, is in gray clay where it is impurities. 
Loss of Mass thus affects porosity and absorption. The results of these properties are shown in Figure 5. The absorbency is directly proportional to the porosity as shown in this graph.

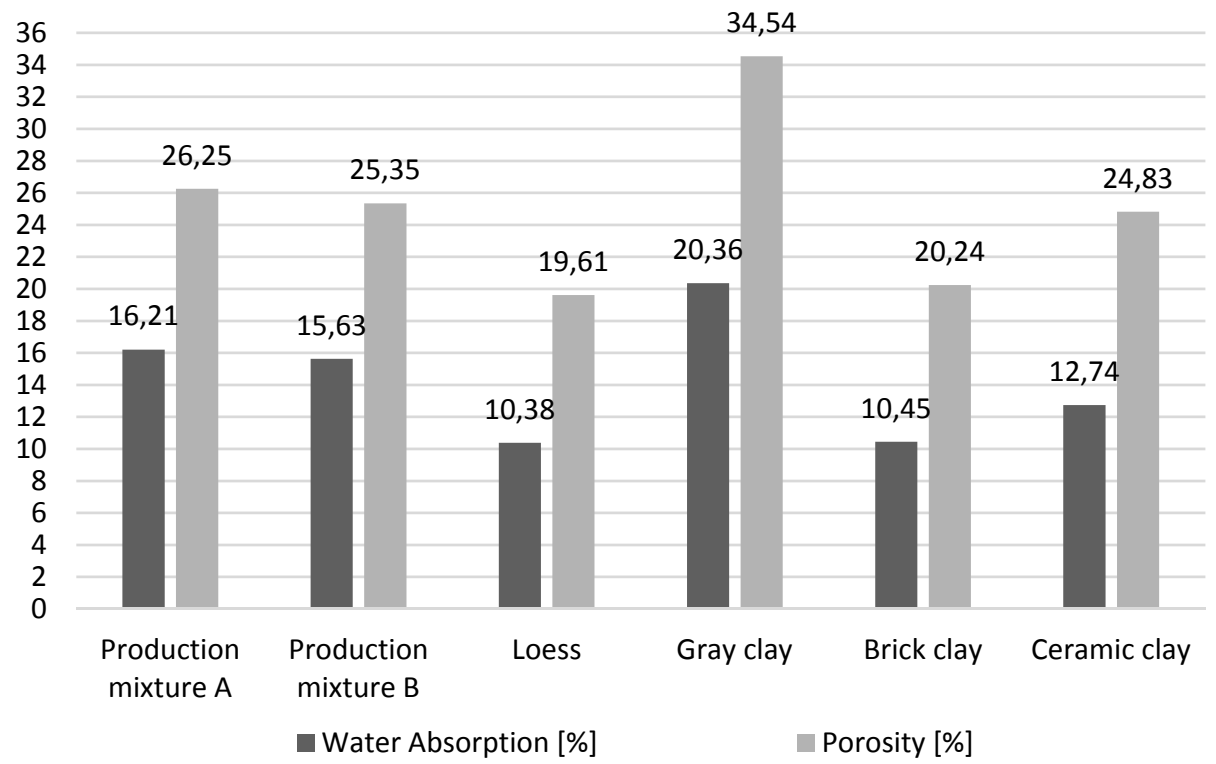

Fig. 5. Graph of Water Absorption, Porosity

Adding the brighter, thus increasing the porosity, reduces the bulk density, as evidenced by the further test, the density test, the results of which are shown in Figure 6.

Due to the addition of lighters burned during firing, the volume of weight was reduced for both production mixtures.

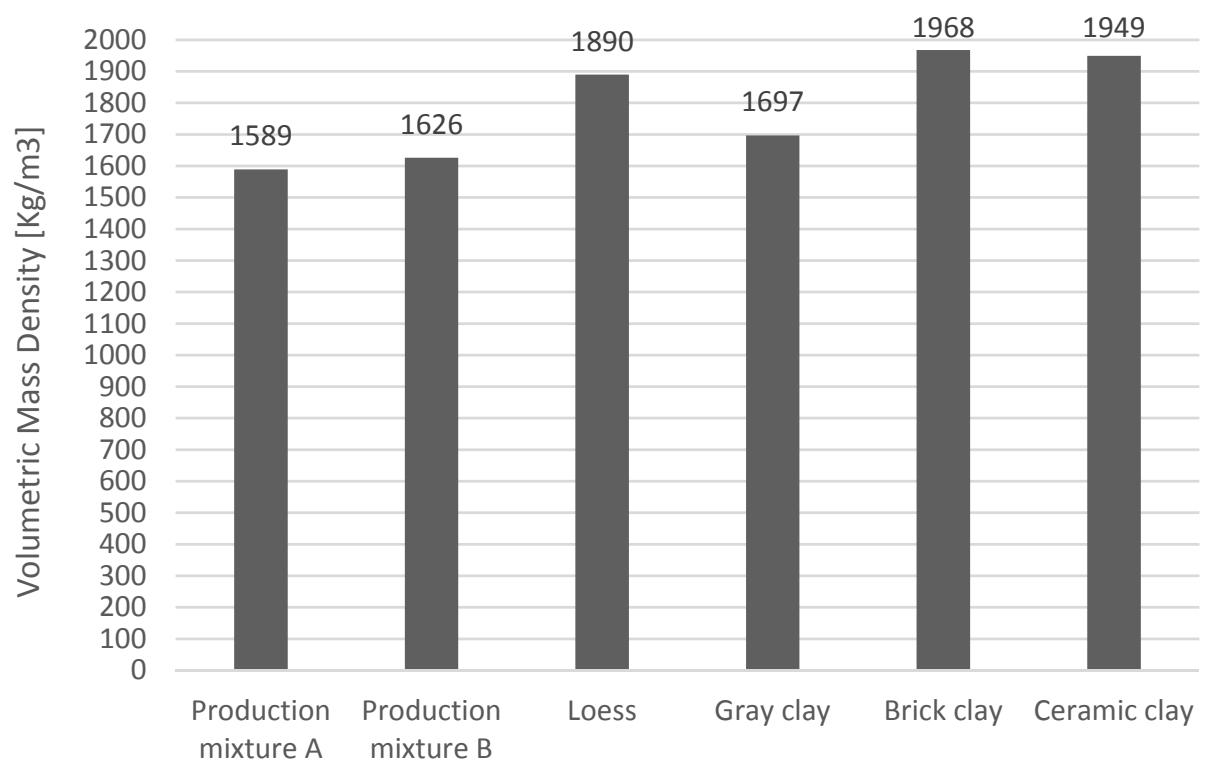

Fig. 6. Graph of Volumetric Mass Density 
From the previous results it is clear that the strength properties of the production mixtures cannot be too high. These expectations confirmed the compressive strength and flexural strength tests, the results of which are recorded in the graph in Figure 7.

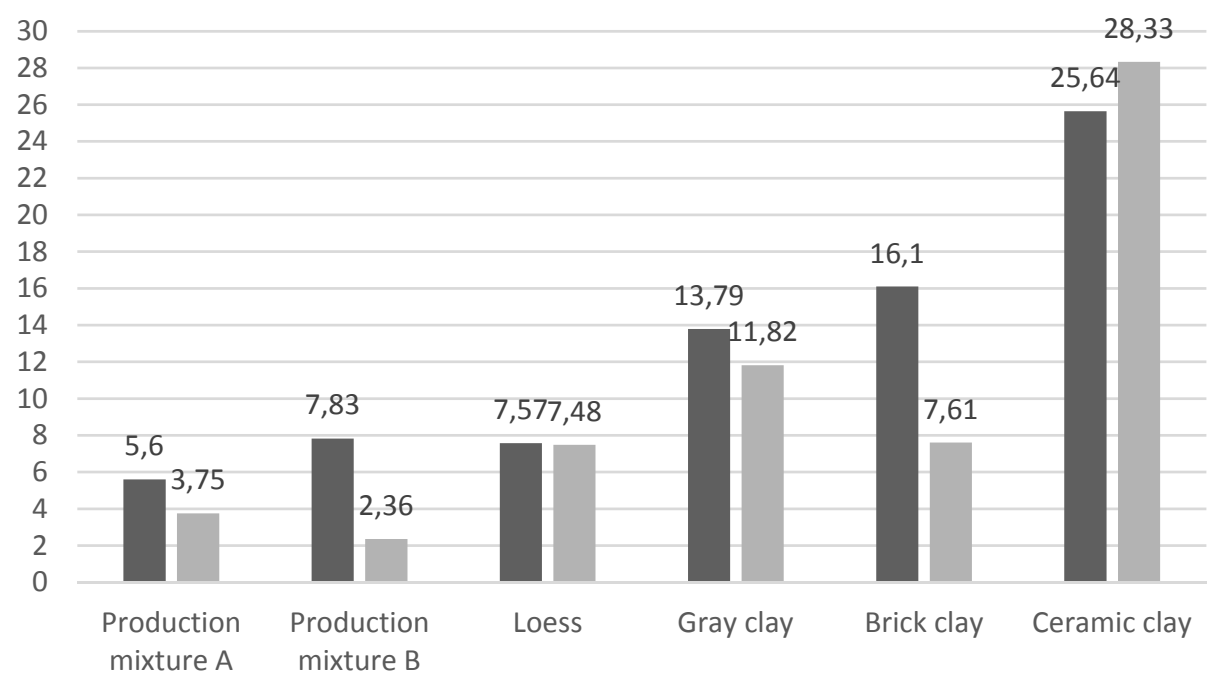

- Compressive strength [MPa] — Flexural strength [MPa]

Fig. 7. Graph of Compressive Strength and Flexural Strength

Particularly compressive strength is very important for brick blocks as they are used for load-bearing perimeter masonry. The strengths of the production mixes were $5.6 \mathrm{MPa}$ and 7.8 $\mathrm{MPa}$, corresponding to the strengths of the brick blocks P6 and P8, i.e. 6 and $8 \mathrm{MPa}$. However, brick blocks must not fall below these values, which happened in this measurement. The highest strength has been achieved by ceramic clay, which must be of high quality, due to the often-thin walls of fired products. Samples after the test Compressive Strength are shown in Figure 8.

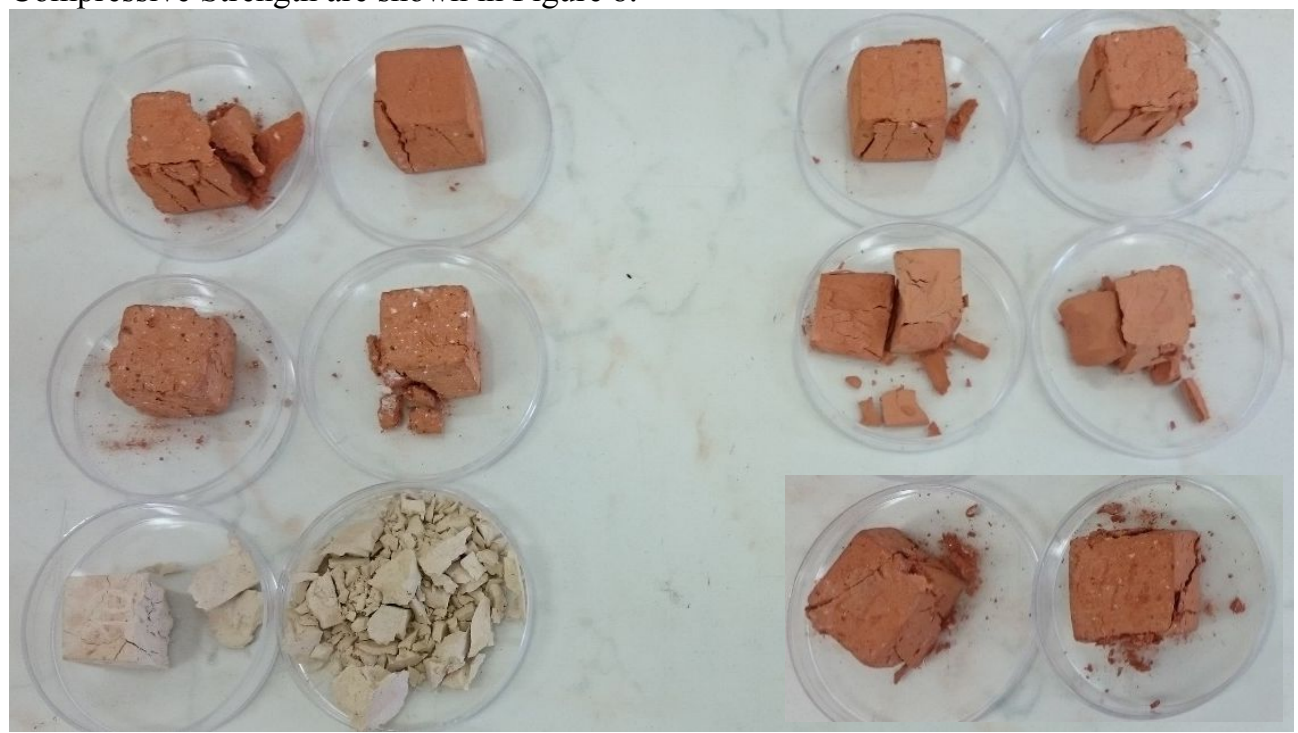

Fig. 8. Samples after the test Compressive Strength 


\section{Conclusion}

After summarizing the results and considering the thermal characteristics of brick fragments, the best option would be to produce brick blocks made of ceramic clay for decorative purposes. Especially thanks to the strength characteristics that are up to five times higher than the classically used mixtures for brick blocks. However, earlier I measured [2] that this soil very well leads heat, which is very inappropriate for the perimeter structures of the buildings. Another problem is financial cost. Because of its quality it is much more expensive.

At present, the development is aimed at reducing the thermal conductivity of the body while maintaining the maximum possible strength. The second way to reduce thermal conductivity is to develop geometry of brick blocks. The third option is to fill cavities with insulating material [3].

The results show the efforts to improve the properties of the production mixtures where all the properties are improved while maintaining the minimum necessary strength. It is best to see the influence of bulk density on strength.

\section{References}

1. L. Zhang, Construction and Building Materials, 47, 643-655, (2013)

2. J. Šál, P. Nováková, Proceedings of 17 th International Multidisciplinary Scientific GeoConference, 367-374 (2017)

3. P. Heinrich, Thermal Insulating Properties of Bricks - Yesterday, Today and Tomorrow. In tzbinfo (2012) 